\title{
As mulheres em Godard: contrapontos à teoria feminista do cinema em Une Femme est une Femme (1961)
}

\author{
Women in Godard: counterpoints to the feminist film theory in Une Femme \\ estune Femme (1961)
}

Rodrigo Cássio Oliveira

Doutor em Filosofia pela Universidade Federal de Minas Gerais e professor e pesquisador da Universidade Estadual de Goiás (UEG).

<rodcassio@hotmail.com>

\section{RESUMO}

A proposta deste artigo é revisitar a teoria do prazer visual de Laura Mulvey por meio de uma análise do filme Une femme est une femme(1961), de Jean-Luc Godard. O lançamento do filme ocorreu quase quinze anos antes de Mulvey publicar suas ideias, mas ele nos oferece um contraponto a algumas das principais teses da autora. A autoconsciência da narrativa, o estilo antiilusionista de Godard e uma protagonista feminina que controla a açãosão elementos que desviam da teoria do olhar masculino no cinema. Desse modo, o filme traz à tona questões que a teoria feminista do cinema viria a discutir décadas depois do artigo de Mulvey, como no exemplo dos estudos de Ann Kaplan sobre as personagens femininas do cinema narrativo dos anos 1980. Para discutir essas questões, o artigo interpreta o filme de acordo com o referencial psicanalítico de Mulvey e Kaplan.

Palavras-chave: Análise fílmica. Cinema moderno francês. Feminismo.

\begin{abstract}
The article's purpose is to review Laura Mulvey's theory of visual pleasure through an analysis of JeanLuc Godard's Une Femme estune Femme (1961). The movie was made about fifteen years before the publication of Mulvey's ideas, but offers a counterpoint to some of article main theses. The self-consciousness of narrative, the anti-ilusionism of Godard's style and the female protagonist who controls the action are deviations from theory of the male gaze in cinema. In this way, the movie presents issues that the feminist film theory discussed decades after Mulvey's article, as in the example of Ann Kaplan's studies about female characters in 1980's narrative cinema. To discuss these issues, this article interprets Une Femme estUne Femme according to the psychoanalytic reference of Mulvey and Kaplan.
\end{abstract}

Keywords: Film analysis. Modern French cinema.Feminism.

\section{Introdução}

Publicado por Laura Mulvey na revista Screen, em 1975, o artigo Prazer Visual e Cinema Narrativo possivelmente constituiu a mais referenciada base de uma teoria feminista do cinema, tendo sido objeto de desenvolvimentos diversos nas últimas décadas, incluindo o trabalho de revisão da própria autora, bastante conhecida e razoavelmente publicada no Brasil. Ao articular conceitos psicanalíticos freudianos a uma análise do cinema como uma forma de experiência subjetiva e prazerosa, Mulvey caracterizou o filme narrativo clássico como a realização de um inconsciente patriarcal. Para a autora, um olhar masculino inerente à forma clássica do cinema objetificaria a mulher, não 
apenas como um objeto a ser visto, mas também como um objeto a ser visto de determinado modo.

Nesse passo, Mulvey foi responsável por transformar os conceitos de voyeurismo e escopofilia em chaves importantes de uma terminologia psicanalítica aplicada ao estudo do cinema. Mais do que prender-seà investigação da construção, nos filmes, das identidades masculinas e femininas, Mulvey tomou o cinema como um dispositivo e uma linguagem, associando o modus operandi da experiência cinematográfica à chamada cultura patriarcal. Dito de outro modo, ela compreendeu o aparato cinematográfico e as convenções estético-narrativas de um determinado cinema - o filme clássico que vigorou na produção industrial dos anos 1930 aos anos 1960 - como provenientes de uma visão de mundo essencialmente masculina, no interior da qual o feminino possuiria um lugar subalterno.

Sem ignorar que as teorias feministas e os estudos de gênero foram bastante debatidos e contam hoje com um sem número de atualizações, este artigo mantém o interesse pelo texto seminal de Mulvey em 1975 como uma forma de aproximação às ideias que circulavam naqueles anos, tendo em vista, sobretudo, a relação entre os filmes modernos e o contexto intelectual que os recebeu. Nosso objetivo não é colaborar para o estado atual do debate nos núcleos de teorização sobre feminismo e gênero, mas sim repassar a formulação teórica das ideias mulveyanascom a finalidade de usá-las como embasamento na análise de um filme do cineasta francês Jean-Luc Godard. Por essa razão, em primeiro lugar, revisitaremos os principais conceitos de Mulvey. Em segundo lugar, por meio da análise de trechos selecionados deUne femme est une femme (Godard, 1961), abordaremos a maneira pela qual o estilo moderno deste filme antagoniza com algumas das principais teses lançadas em Prazer Visual e Cinema Narrativo. Quando oportuno, iremos ao encontro de proposições desenvolvidas mais recentemente pela pesquisadora norte-americana Ann Kaplan (1995), cuja percepção da masculinização das protagonistas mulheres no cinema narrativo do final do séc. XX é relevante para a análise do nosso objeto de estudo.

Ao usar as características do próprio medium cinematográfico para atestar os seus argumentos acerca do prazer visual, Laura Mulvey dificultou o vislumbre de um cinema narrativo em que o distanciamento crítico e a metalinguagem pudessem complexificar a discussão sobre a identidade de gênero no cinema, ao mesmo tempo quecomplexificasse a própria constituição psicológica dos personagens e a relação deles com os espectadores. O filme realizado por Godard em 1961, mais de uma década antes de Mulvey ter lançado o seu artigo, é exemplo de um cinema narrativo dessa natureza, e por esse motivo antecipou um discurso dialógico e crítico com as ideias da autora feminista. 
Prazer Visual e Olhar Masculino: quem é dono do olhar?

Ao determinar o cinema clássico de Hollywood como seu foco de maior interesse, Mulvey referiu-se ao conceito de falocentrismo como um marco teórico para compreender a ordenação da sociedade em favor do masculino: "A função da mulher na formação do inconsciente patriarcal é dupla: ela simboliza a ameaça de castração pela ausência real de um pênis, e, em conseqüência, introduz seu filho na ordem simbólica" (Mulvey, 2003, p. 438). Na sociedade falocêntrica, em que o patriarcalismo objetificaria as mulheres por meio da linguagem, a mulher seria significante, e não produtora de significado. Para Mulvey, o cinema clássico é um sistema de representação e uma fonte de prazer erótico (visual) que reproduz a fórmula do prazer patriarcal centrado na sexualidade masculina. $O$ homem é ativo, a mulher é passiva. $O$ olhar do cinema é um olhar masculino que pode ser entendido em três vias: ele se manifesta no olhar do espectador, no olhar da câmera e no olhar dos personagens masculinos sobre as personagens femininas. Em todos eles, a mulher é submetida como um elemento recebedor, sendo preparada e entregue como tal em um mecanismo de assujeitamento cinematograficamente guiado.

Para entender o olhar masculino do cinema clássico, de acordo com Mulvey, as noções de escopofilia evoyeurismosão fundamentais. O voyeurismo, quando obsessivo, é a modalidade de perversão que resulta da escopofilia. Esta é, por sua vez, uma etapa do desenvolvimento sexual - muito frequente em crianças, quando próximas da fase edipiana - em que o investimento libidinal recai sobre o objeto a ser visto, realizando-se na atividade do olhar. O prazer de ver é um fenômeno relacionado a esta etapa da formação mental, levando Mulvey a afirmar que o cinema é um tipo de aparato estreitamente ligado à escopofilia: "Embora o filme esteja realmente sendo mostrado, esteja lá para ser visto, as condições de projeção e as convenções narrativas dão ao espectador a ilusão de um rápido espionar num mundo privado" (Mulvey, 2003, p. 441).

Por um lado, a autora refere-se à relação entre o espectador, a tela luminosa e o ambiente escuro, sendo todo o universo particular da experiência cinematográfica elaborado de modo a separar a diegese e o espectador numa relação tipicamente voyeurista: o prazer de ver éafirmado pela lógica da projeção fílmica, bem como por suas condições físicas. Por outro lado, Mulvey tem em conta a estrutura narrativa do filme clássico, compreendendo especialmente a construção dos personagens e as suas relações intradiegéticas, ou seja, a função que os personagens possuem na trama, o jogo de causa-consequência que os envolve, o encadeamento teleológico da ação etc.

Mulvey considera que a escopofilia no cinema clássico é de tipo narcísico, atendo-se às formas humanas e promovendo a identificação do espectador na 
medida que este se despe, ilusoriamente, de seu próprio ego, rendendo-se enfim a uma subjetividade idealizada (isso ocorre com os heróis dos westerns, por exemplo, por meio de ícones como John Wayne). O ilusionismo da linguagem cinematográfica é um sustentáculo importante dessa identificação, uma vez que os princípios ilusionistas de filmagem e montagem reproduzem, melhor que em qualquer outro modo de linguagem cinematográfica, condições de apreciação estética muito próximas das formas naturais da percepção visual, equiparando o universo fílmico ao mundo objetivo da experiência social.

Em termos gerais, temos uma separação e uma aproximação que dizem respeito às personagens masculinas e femininas (as respectivas identidades eróticas) tal como são construídas no filme clássico. A escopofilia separa a pessoa do espectador e a da personagem, tornando a segunda um objeto de estímulo visual, um ponto de chegada do olhar que se compraz em ver. O narcisismo, por sua vez, põe em cena o ego do espectador, que se projeta na personagem, deslocando imaginariamente a subjetividade ativa em direção ao encontro com o mundo da diegese. Ali, a satisfação é propulsora do desenvolvimento dos eventos narrativos. No primeiro caso, o espectador busca o outro. Nos dois casos, "o homem controla a fantasia do cinema e também surge como o representante do poder num sentido maior: como o dono do olhar" (Mulvey, 2003, p. 445, grifo nosso). Um dos principais artifícios pelos quais o cinema clássico concede ao homem este poder é o da proposição de personagens masculinos como iniciadores e controladores da ação, "de forma que o poder do protagonista masculino, ao controlar os eventos, coincida com o poder ativo do olhar erótico, os dois criando uma sensação satisfatória de onipotência" (Mulvey, 2003, p. 446).

Como se daria, em particular, a representação da mulher? Para responder a essa pergunta, Mulvey chama a atenção para a importância do complexo de castração na manutenção da ordem simbólica. O risco da castração causaria ansiedade no homem, que procuraria resolvê-la por meio da escopofilia fetichista, ou do voyuerismo - uma resolução decidida pelos aspectos específicos da representação no âmbito da narratividade. Em certos filmes fetichistas (Mulvey exemplifica com o cinema de Sternberg) o que se dá é uma rejeição da castração, adornando o objeto até transformá-lo em algo agradável por si mesmo. Como na formação do star system de lindas atrizes hollywoodianas, a mulher é bela, modelar, levando à última instância a sua condição de objeto do olhar masculino. Em outros filmes, como nos de Hitchcock - ou no filmnoir como um todo -, a ansiedade da castração acarreta a culpabilização da mulher, que é punida ou perdoada, confrontando-se com o poder da lei, sempre a cargo 
de um personagem masculino, regulador da ação e capaz de abalizar a ordem social ameaçada pela perniciosidade da mulher.

Em artigo publicado no final dos anos 1980, Mulvey (2005) viria a enfrentar problemas que não foram suficientemente esclarecidos em Prazer visual e cinema narrativo. Sobre a caracterização do olhar do cinema como um olhar masculino, a autora respondeu à objeção de que as espectadoras femininas não pareciam ter um lugar bem definido em sua relação com o filme clássico, já que este se apresentava como uma espécie de invólucro acondicionado pelo patriarcalismo. Sem abandonar a essência da sua tese principal, Mulvey enfatizou o olhar masculino como uma posição, um ponto de vista perpetrado pelo filme clássico. O cinema que o propaga dependeria de um tipo de experiência que se volta exclusivamente para o público masculino, deixando as espectadoras sempre à deriva. A posição masculina poderia ser analisada a partir da própria apreensão das mulheres do público, isto é,"da mulher na posição de espectadora, assumindo o lugar masculino do olhar e do prazer, revivendo o que seria para a psicanálise o aspecto perdido da sua sexualidade" (Maluf et al., 2005).

\section{Godard no cinema francês dos anos 1960}

Entre os anos 1950 e 1960, o cinema francês constituiu um dos principais polos deflagradores do que viria a ser conhecido, na história do cinema, como o seu momento moderno. O cinema clássico, em especial o produzido nos estúdios norte-americanos e exportado como produto e forma ideal para outros países, encontrava-se em crise desde o final da Segunda Guerra Mundial. Hollywood enfrentava a reestruturação das suas diretrizes de produção, exigida legalmente pela contestação da política de trustes dos anos 1930 e 1940 . Ao mesmo tempo, as transformações culturais da década de 1960, com a elevação de um contexto de crise do mundo ocidental - a Guerra Fria, o impacto da Revolução Cultural Chinesa, a chamada contracultura nos EUA -, transformaram o período em momento propício para um cinema jovem, disposto a originar filmes marcados pela rebeldia formal em relação ao modelo clássico.

Esse período do cinema francês tornou-se vastamente conhecido pelo nome de nouvelle vague. Até o ponto culminante do surgimento dos filmes, a sua base teórica foi articulada na revista Cahiers du Cinéma, fundada no começo dos anos 1950 pelo crítico André Bazin. Nela, muitos dos principais diretores do movimento se revelaram, inicialmente, como críticos. Um desses diretores é Jean-Luc Godard, e um dos filmes de Godard, lançado em 1961, leva o nome de Une fermme est une femme (Uma mulher é uma mulher). Assim como em outras realizações da época, inclusive outras realizações do próprio Godard, o filme lança mão da desconstrução dos códigos narrativos que balizaram o 
cinema clássico hollywoodiano, colocando esses códigos em perspectiva e modernizando a linguagem cinematográfica.

Une femme est une femme narra o conflito de um casal, Angela (Anna Karina) e Émile (Jean-Claude Brialy), em torno do desejo de Angela por ser mãe. Émile trabalha em uma revistaria no centro de Paris. Angela, por sua vez, trabalha como stripper em um bar voltado para o público masculino. Ambos têm um amigo em comum, Alfred (Jean-Paul Belmondo), personagem que diz amar Angela e se esforça por ela, sem muito sucesso. No decorrer da narrativa, Angela descobre que está em seu dia fértil, mas Émile não aceita a ideia de ser pai e reage aos pedidos de Angela com ironia, insinuando que Alfred poderia engravidá-la. Ao articular o seu próprio desejo aos desejos de Émile e Alfred, Angela finalmente consegue que o companheiro se disponha a engravidá-la, usando como argumento o fato de ter cedido espontaneamente aos cortejos de Alfred.

Oqueéuma mulher? A pergunta vem de um Godard que se revelava, desde os primeiros curtas-metragens, um cineasta atento às questões relacionadas ao feminino. As mulheres de Une femme coquette (1955), Acossado (1959) ou Charlotte etson Jules (1960), todos anteriores a Une femme est une fermme, lidam invariavelmente com circunstâncias que problematizam as relações entre o masculino e o feminino. Também em filmes posteriores a Une femme est une femme, até a participação de Godard no coletivo maoísta DzigaVertov, as personagens femininas do diretor francês foram marcadas por dilemas sobre poder e sexualidade. Filmes como Vivresavie (1962) ou Une femmemariée (1964) estão certamente entre as mais sofisticadas representações do feminino no cinema, com personagens mulheres interessantes e, a nosso ver, desafiadoras para uma teoria como a de Laura Mulvey.

\section{Autoconsciência e antiilusionismo: quem controla a ação?}

Diante do argumento mulveyano de que o homem é o dono do olhar no cinema narrativo, uma primeira aproximação analítica a Une femme est une femme deve ressaltar o altíssimo grau de autoconsciência da narrativa deste filme. De fato, como observado por Robert Stam (1981, p. 34), "o antiilusionismo e a desmistificação são o cerne do método e das preocupações artísticas de Godard". Se o cinema clássico se definiu como um tipo de narração que vincula o espectador ao mundo diegético buscando o máximo de objetividade e fluência narrativa, a ruptura godardiana com o ideal da transparência foi uma contribuição fundamental para caracterizar a parcela autorreflexiva, lúdica e metalinguística do cinema moderno dos anos 1960-70. Em vez de inibir as intervenções da câmera como uma mediadora ativa na construção do universo 
diegético, Godard celebrizou-se pela busca da materialidade do processo criativo, pela concepção de personagens conscientes de sua condição de personagens e pelo emprego de um estilo narrativo, sonoro e visual que se afasta completamente da ideia de imersão típica do filme ilusionista clássico. ${ }^{1}$

Ainda que se trate de um filme narrativo que respeita normas básicas do cinema clássico (personagens que fazem avançar um enredo com papéis definidos e não cambiáveis, uma mise en scène em espaço e tempo bem delimitados, continuidade narrativa etc.), Une Femme est une Femme faz com que a participação do espectador no jogo de representação seja constantemente ressaltada. Existem objetivos claros (Angela quer ter um filho) e ações encadeadas em vista de um fim último (a relação de Angela e Alfred vai se construindo continuamente, até a cena final em que ela consegue o que desejava de Émile), mas nada disso estimula uma audiência alheia e dirigida pelo desenvolvimento da ação. Ao contrário, já na primeira sequência, Angela propõe um pacto de mútuo reconhecimento com o espectador. Ao se sentir atraída por um rapaz que toma café ao seu lado no balcão de um típico café parisiense, a personagem sai de cena lançando uma piscadela para a câmera, como se pedisse ao espectador para guardar aquele momento como um pequeno segredo.

Ao mesmo tempo em que a elevada autoconsciência de Angela imprime ao jogo de faz-de-conta de Une Femme est une Femme um estilo bastante diferente daquele que se baseia na separação rígida entre o espectador e a diegese, a intimidade exclusiva da personagem com o público a coloca no centro das atenções, valorizando os seus julgamentos e desejos. Mais que isso, Angela toma para si o papel de desencadeadora das ações narrativas, uma vez que todos os acontecimentos que levam a história adiante dependem de sua anuência ou recusa - isto quando já não são os próprios interesses de Angela que obrigam os personagens homens a agirem; o disparo da narrativa, por exemplo, se concentra inteiramente no seu incontrolável desejo de ser mãe.

Um recurso similar ao da cena de abertura pode ser observado quando Émile e Angelaencontram-se em casa pela primeira vez. Angela descobriu que estava em seu dia fértil, e planeja pedir a Émile que a engravide. Émile, por sua vez, chega do trabalho interessado apenas em acompanhar um jogo de futebol pelo rádio, ler tranquilamente o jornal e jantar em casa sem maiores

1 A nossa referência para a definição de cinema narrativo clássico são os estudos de David Bordwell (1986), para quem esse estilo narrativo é caracterizado pela onisciência dos eventos narrados, a alta comunicabilidade com o espectador e uma autoconsciência muito discreta. Em Godard, a destacada autoconsciência narrativa de filmes como Une Femme est une Femme é um dos elementos que diferenciam o seu estilo em relaçãoao modelo clássico. Uma análise bastante elucidativa do cineasta francês, do ponto de vista narratológico, pode ser lida no último capítulo de Narration in theFictionFilm (Bordwell, 1985, p. 311-32). 
preocupações. Nesta ocasião de crise conjugal, evento tão conhecido no cinema clássico, Angela e Émile preparam com bom humor e distanciamento dramático o desenlace do seu próprio conflito, de modo que a cena é tão pouco realista quanto mais são acentuadas a retórica dos discursos e o antiilusionismo da miseenscènegodardiana.

O enquadramento da cena capta o casal em um cômodo diferente daquele em que está a câmera. Da sala, onde está a câmera, vemos a cozinha, onde está o casal. A disposição do cenário transforma a porta que separa os dois ambientes em um tableau. Assim enquadrados, prestes a encenar a discussão conjugal, Angela alerta Émile para a necessidade de saudar o respeitável..., referindo-se a quem está do outro lado do tableau, istoé, os espectadores. O reconhecimento de que o público está presente reforça continuamente o caráter farsesco da intriga conjugal. O respeito com que Angela não se esquece de cortejar o público é o de uma personagem que se oferece aos seus observadores, gentilmente, como a controladora da ação. Do ponto de vista da construção da personagem, a estratégia aumenta a simpatia de Angela e contribui para que as suas armações sejam benquistas pelo público, que tende a torcer por ela.

A desconstrução criativa do ilusionismo clássico está presente também em outros filmes modernos que cercavam Godard nos anos 1960. Em Muriel (1963), de Alain Resnais, encontramos uma estratégia de miseenscènesemelhante na cena que inicia o desfecho da narrativa. Os principais personagens estão reunidos para o almoço de domingo, e os planos brevíssimos parecem colidir com o exagero proposital das atuações e do texto, sempre entrecortado e inconclusivo. Um plano geral com a câmera distante das personagens dura apenas o suficiente para que a viúva interpretada por DelphineSeyrig abra uma grande cortina que ocultava o espaço de convivência e permitia que a câmera captasse apenas um espaço fechado, inacessível, encoberto. O gesto da personagem lembra a abertura das cortinas de um teatro, isto é, o lugar por excelência da encenação, o locus tradicional da mentira tomada como verdade. No gesto da atriz, a ideia de um desmascaramento dos demais personagens vem à tona como o significado da cena, antecipando o comportamento intempestivo de outro personagem à mesa.

Assim como Godard, Resnais faz uma crítica da vida privada como farsa. No entanto, se Resnais opta por uma insidiosa afronta à honestidade da cena dramática naturalista, Une femme est une femme atenua o potencial calamitoso da situação de conflito romântico. Godard não se presta a denunciar a família como um âmbito de relações sociais que perdeu a função original. $O$ seu interesse está voltado, antes, para as dimensões da ambiguidade e da ironia, avessas a 
qualquer sinal de melodrama. ${ }^{2}$ Angela e Émile vivenciam uma espécie de farsa consentida, ignorando o aspecto sôfrego ou vitimizador deste destino, como se as diferenças do casal não implicassem a gravidade, desolação e ressentimento que se poderia esperar da representação delas em um filme clássico - por exemplo, nos filmes de vonSternberg, como os que Mulvey tinha em mente ao escrever Prazer Visual e Cinema Narrativo.

\section{Blonde Venus x Une Femme estune Femme}

Retomando a tese de Mulvey sobre a relação entre o prazer visual escopofílico da espectatorialidade cinematográfica e a fetichização das personagens mulheres, cabe perguntar: De que modo operaria a fetichização de uma personagem como Angela? De que modo o estilo antiilusionista e a narrativa autoconsciente de Godard lidaram com os princípios do olhar masculino que Mulvey atribui ao cinema clássico? Se a personagem vivida por Anna Karina efetivamente detém o controle da ação, poderíamos concluir que ela é autoconsciente inclusive da sua condição de objeto de um suposto olhar masculino?

Em BlondeVenus (1932), de Sternberg, encontramos um caso interessante para comparar com Une Femme est une Femme. Ao analisar este filme, a teórica feminista Ann Kaplan observa que a fetichização de Helen, personagem vivida por Marlene Dietrich, se dá pela oposição entre sensualidade e maternidade. Helen é uma esposa que em diferentes ocasiões se vê dividida entre a vida familiar e a profissão de dançarina em uma boate, isto é, entre o cuidado com os filhos junto ao marido e a sensualidade pujante da sua ocupação noturna. No entendimento de Kaplan (1995, p. 84), "o patriarcado vem representando a Mãe como fora do âmbito da sexualidade e, portanto, se quisermos uma determinada definição, não-ameaçadora para o homem".

Com efeito, o fetichismo é abordado por Kaplan como uma forma de perversão que atribui às mulheres características físicas associáveis ao falo. Neste sentido, a maternidade e a ausência de sexualidade seriam dados correspondentes que se imbricam na construção de uma personagem como Helen. Kaplan sustenta que os vários meios pelos quais a personagem de Dietrich é fetichizada como dançarina (o uso de saia reta, os saltos altos, os paetês nas roupas etc.) são uma compensação para os momentos em que ela assume a condição de mãe e precisa abdicar da sensualidade. A primeira cena de exibição de dança seria um exemplo de que o estilo de Sternberg colocou-

2 Sobre a importância do melodrama como matriz das atualizações do cinema narrativo clássico, conferir Ismail Xavier (2003). 
se a serviço da fetichização. Trata-se de uma longa sequência em que Helen dança sob o olhar atento do homem rico vivido por Cary Grant (três olhares masculinos, como proposto por Mulvey: o do personagem, o da câmera e o dos espectadores). Apaixonado pela dançarina, o personagem de Grant desencadearia a perturbação da vida familiar, confirmando que Helen, ao contrário de Angela, não detém o controle da ação.

Em Une femme est une femme, a cena de BlondeVenus ecoa no momento em que vemos Angela exibindo seu número de striptease. A diferença de abordagem dos dois filmes demonstra o quanto, de fato, o controle da ação acaba sendo fundamental na construção das personagens mulheres.

No filme de Sternberg, Helen voltou a dançar depois de alguns anos distante dos palcos, porque precisava financiar o tratamento de saúde do marido. Apesar de possuir um talento singular e promissor, a dançarina havia abandonado a profissão para se casar e ser mãe, desafiando a resistência do próprio marido que, embora doente, nunca se sentiu confortável por depender da esposa. Em Une Femme est une Femme, por sua vez, Angela é stripper com a anuência de Émile. O parceiro não apresenta sinais de incômodo, e, quando apresenta, recebe uma resposta desconcertante (Émile se diz enojado por Angela se despir em público, ao que ela responde que o salário do namorado não é suficiente para viverem juntos). Longe da moral melodramática de BlondeVenus, Godard define Angela como uma mulher que, tendo em vista tornar-se mãe, aprofunda a sua sexualidade e confronta os personagens homens do início ao fim da narrativa. Para isso, como veremos na análise da cena de strip, ela faz uso de uma argúcia indissociável da sua condição de mulher desejada pelos olhares que a cercam. Se é possível falar em olhar masculino, aqui, este olhar é assimilado por Angela em benefício próprio - e isso não se dá apenas na diegese, mas também em relação ao olhar dos espectadores, dada a elevada autoconsciência da narrativa e as quebras com o ilusionismo que aproximam o público da intimidade da personagem (uma aproximação que é diferente da espionagem do mundo privado, para lembrar a afirmação de Mulvey sobre a tela do cinema como uma espécie de buraco de fechadura).

Há uma importante cena intermediária em Blonde Venus, quando Helen já se tornou uma estrela dos palcos e seus shows são vistos por um grande público. Em um destes shows, o figurino de Dietrich é rico em adornos fetichistas, como uma cartola e um terno brancos (vestimenta clássica masculina). Tais objetos vestuais, segundo Claire Johnston (apud Kaplan, 1995, p. 80), denotariam que "a mulher como signo torna-se o pseudocentro do discurso fílmico", já que "a verdadeira oposição proposta pelo signo é masculino/não-masculino". Em outras palavras, ao se distanciar da vida familiar, Helen se torna carente do 
aspecto masculino, de modo que a sua decadência pessoal seria revogável apenas por meio do arrependimento.

Em Une femme est une femmehá uma cena similar, que o estilo godardiano resolve de maneira muito diversa. Esta cena é o momento de maior fetichização de Angela, e é ela que vamos analisar a seguir.

\section{A fetichização de Angela}

A sequência dura pouco menos de três minutos e compreende toda a passagem de Angela pelo trabalho, desde o momento em que ela chega à casa dançante até o momento em que conclui o seu número de strip, olhando para a câmera em um primeiro plano bastante próximo. A preparação de Angela e a expectativa do seu número é acompanhada por uma voz off presente na diegese, mas ausente do quadro (o dono da voz é uma espécie de animador de auditório, que anuncia e comenta os números de striptease). No primeiro plano da sequência, vemos Angela se voltar para dentro da cabine, logo após dialogar, pela cortina, com uma colega de trabalho. A profundidade de campo, nos enquadramentos do diálogo, mostra mulheres que transitam e esperam a vez de se apresentarem. Já dentro da cabine, Angela usa um vestido branco com detalhes vermelhos, uma cor frequente no seu vestuário, deixando as costas visíveis. A este primeiro detalhe fetichista podemos somar o cigarro da personagem, que ela descansa no cinzeiro enquanto lê a partitura da música que está prestes a interpretar.

Filmada com câmera na mão, a cena ganha um enquadramento mais equilibrado quando Angela se senta em frente ao espelho, de costas para a câmera. Um movimento de travelling para baixo, acompanhando a atriz, localiza a sua silhueta entre os objetos que preenchem o espaço da cabine. No movimento que ajusta o plano, Angela retira um chapéu de marinheiro da cabeça de um urso de pelúcia que estava atrás do seu assento. $O$ urso é realçado por um novo enquadramento, quando percebemos que ele também possui uma fita vermelha. Assim que Angela se levanta para começar a dançar, a voz off anuncia para todos os homens do público (e também para os espectadores de Une Femme est une Femme):

Serão como o homem

que viu o homem

que viu o homem

que viu o homem

que viu o urso 
Esta fala em off pode ser lida como a citação de um conto popular sobre a falta de objetividade das histórias que circulam quando as pessoas que as contam não as vivenciaram diretamente ${ }^{3}$. O animador de auditório, porém, modifica a versão original do ditado. No seu uso comum, o conto se refere apenas ao homem que viu o homem que viu o urso. Para a voz off de Une femme est une femme, no entanto, dois outros homens são acrescentados como intermediários.

Quais seriam as leituras possíveis para essa modificação do dito popular apropriado por Godard nesta cena? A presença do urso de pelúcia no camarim de Angela não poderia ser negligenciada, acenando para uma interpretação possível. Por certo, poucas coisas são mais coerentes com o projeto de cinema godardiano que a apropriação de um conto popular sobre as mediações, os ruídos e a complexidade da comunicação em um espetáculo artístico. $O$ texto da voz off é coerente com o estilo autoconsciente da narrativa de Une Femme est une Femme, colocando em perspectiva o stripde Angela, como se quisesse considerá-lo uma metáfora da expressividade artística e, em última instância, da própria experiência cinematográfica dos filmes clássicos. O espetáculo do cinema nunca dá a ver a própria realidade, assim como o espetáculo de Angelanão dá a ver o próprio urso, mantendo-o oculto por trás das cortinas. 0 conceito de olhar vem à tona nesta passagem do filme de Godard, e o contexto da cena na narrativa nos dá motivos para acreditar que se trata da elaboração cinematográfica de uma série de problemas que Laura Mulvey viria a discutir, referindo-se a temas como a representação das mulheres, o desejo, a sexualidade e o olhar masculino.

Se BlondeVenus mostra Helen vestindo um terno masculino em sua cena de dança, Godard veste Angela com trajes de marinheiro para que ela faça seu strip em Une Femme est une Femme. Esta masculinizaçãoda personagem é a principal fetichização de Angela na cena, e nos oferece uma chave para explicar o ditado popular que o locutor utiliza na apresentação. Angela poderia ser um dos homens que viu o urso, já que ela de fato viu um urso, no camarim, pouco antes de ir ao palco. Esta explicação, contudo, é incompleta. O ditado pronunciado pela voz off se refere a cinco homens. Levando em conta a autoconsciência narrativa que aborda os espectadores diretamente, poderíamos distribuir todos os olhares envolvidos na cena em diferentes níveis de visibilidade, a fim de esclarecer o misterioso anúncio do narrador:

3 Algo como a brincadeira do telefone sem fio, muito conhecida no Brasil. 


\begin{tabular}{|l|l|}
\hline 1 - Serão como o homem & Os espectadores ("serão como homens") \\
\hline 2 - que viu o homem & O público da casa dançante (homens) \\
\hline 3 - que viu o homem & Angela vestida de marinheiro ("masculinizada") \\
\hline 4 - que viu o homem que viu o urso & $?$ \\
\hline
\end{tabular}

O narrador off está se dirigindo primeiramente aos espectadores do filme (primeiro nível de visibilidade). Estes espectadores veem os homens que, na plateia da casa de dança, se comprazem ao verem Angela despindo-se. No terceiro nível está Angela, cuja fetichização permite que a consideremos como um homem. Mas quem estaria no quarto nível? Quem Angela teria visto, que por sua vez teria visto originalmente o urso?

Uma leitura psicanalítica parece adequada para responder a essa pergunta. Angela teria visto o homem que impulsiona o trauma edipiano, isto é, a figura do pai, por quem a criança nutre sentimentos contraditórios e tão mais conflitantes quanto maior é o seu desejo de matá-lo. Como conhecido desde a obra de Freud, o ponto de vista infantil não apenas nota que este pai tem autoridade decisiva sobre a mãe, mas também que ele representa o perigo de castração, do mesmo modo que a ausência do falo na mulher. A apostar na relevância desta interpretação baseada em conceitos da psicanálise, poderíamos dizer que Angela é a mulher que, aliviando o temor da castração, viu e fez desaparecer aquele que de fato viu o urso. Este seria mais um elemento de fetichização da personagem, operando no nível interpretativo da narração e da miseenscène.

O controle que Angela exerce sobre o urso de pelúcia parece atestar essa interpretação. Obviamente, trata-se de um objeto inanimado, um urso que não impõe perigo, mas que só pode sê-lo porque o pai já não está presente, não existindo a representação de um adversário pelo afeto materno. A presença do pai, o homem que viu o urso, é barrada pela cena, aliviando o temor de castração. Angela retira da pelúcia o chapéu que talvez vestisse seu pai desaparecido. Vero urso pode ser uma alegoria do trauma edipiano, sobretudo quando observamos que apenas Angela viu o homem que viu o urso; ou seja, a sua relação com o pai foi uma experiência subjetiva única, como não poderia deixar de ser. A ausência do pai, agora, é um requisito para a sensualização da personagem, uma vez que maternidade e sexualidade são inconciliáveis. Angela não quereria tomar o lugar da mãe, naquele momento. Com a ausência do pai, a sexualidade de Angela aflora e pode ser vista por outros homens.

Não se pode negar que todas essas associações e metáforas dão a impressão de overinterpretation em relação a uma cena que talvez expresse um 
significado bem menos denso do que os conceitos psicanalíticos levam a ter. Mas a continuidade da sequência de dança traz novos e interessantes aspectos a serem observados, numa mesma linha interpretativa.

Ao se dirigir para a vitrola que tocará a trilha musical do seu strip, a personagem é acompanhada por um travelling lateral até ser enquadrada no centro do quadro, de perfil para a câmera. Na parcela da direita do quadro, ao fundo, em profundidade de campo, um menino é colhido nos braços pela mãe, que segue aproximando-se da câmera, em trajetória diagonal, até sair completamente de cena. Nessa trajetória em que mãe e filho passam atrás de Angela, as duas mulheres não trocam olhares, cumprimentando-se apenas com a voz. Podemos afirmar que a mulher com a criança é uma figuração do desejo de Angela pela maternidade.

A miseenscène que separa Angela de uma mãe com seu filho nos diz que o objetivo da protagonista não pode ser realizado enquanto ela estiver ocupando o polo oposto ao da maternidade, ou seja, enquanto ela estiver vivenciando a sexualidade, fetichizada como objeto para os vários níveis de ol hares masculinos que o locutor da cena comenta. Assim como em Blonde Venus, sexualidade e maternidade são referidas aqui como experiências antagônicas, muito embora Godard venha a resolver este antagonismo ao seu próprio modo.

No mesmo plano, um último elemento fetichista ainda é anunciado pela voz off, associando Angela ao falo:

\section{A gente precisa admirar a Torre Eiffel, mas eu prefiro a Angela, que é um monumento.}

A fetichização de Angela chega ao ponto máximo na última estrofe da canção que ela interpreta enquanto tira a roupa. Angela assume a sua crueldade (o temor da castração). Ao mesmo tempo, ela também admite que a sua beleza alivia este temor, sendo este o motivo pelo qual os homens a desejam. Difícil imaginar uma verbalização mais objetiva do processo de fetichização que a estrofe final cantada por Angela, em um primeiro plano bastante próximo e olhando para a câmera (logo, para os espectadores):

Sou uma garota má

sou muito cruel

mas os homens nunca protestam

porque sou muito bela 
Duas perguntas parecem se impor ao final dos trechos de Une Femme est une Femme analisados acima. A autoconsciência narrativa de Godard não seria um obstáculo para que o olhar masculino se realizasse de acordo com o esquema descrito por Mulvey? Faz sentido compreender o cinema como um instrumento ideológico-patriarcal em um filme que abarca o espectador de maneira tão autorreflexiva como este? A produção de Angela, por si só, não subverte o padrão clássico de apresentação física da mulher à câmera. Mas isso implicaria que a câmera se comporta a favor de uma erotização da personagem do modo que a leitura psicanalítica de Mulvey propõe? Ou, ainda, isso implicaria que a personagem é uma refém passiva da fetichização, e não uma produtora de significado?

Quanto a essa última interrogação, a função de protagonista de Angela, que jamais perde as suas características femininas, garante o domínio da personagem sobre a câmera, lançando dúvidas sobre a ideia de objetificação pelo olhar masculino supostamente intrínseco ao aparelho. O mesmo pode ser dito em relação aos outros olhares que Mulveychama de masculinos: o dos personagens homens e dos espectadores, uma vez que Godard concebe essas duas instâncias de maneira crítica e autorreflexiva. Por essa razão, a cena do stripde Angela, como demonstramos acima, contribui surpreendentemente para as discussões que Laura Mulvey levantaria apenas mais de uma década depois do filme.

Angela articula a trama de Une Femme est une Femmea fim de realizar o desejo de ser mãe, até o ponto em que ela própria afirma que a sua feminilidade é um aspecto definidor e conclusivo, como veremos no comentário da cena final do filme. A autoconsciência de Angela a respeito da sua condição de mulher depõe a favor da construção da sua identidade. Ela é dançarina, ao mesmo tempo uma mulher que quer ser mãe, e também uma amante, sem deixar de possuir nenhuma destas dimensões como essenciais à sua identidade. Bela e cruel, esta personagem complexa desvia da simples apropriação pelo que se poderia chamar de um olhar masculino, na medida que redireciona os afetos que a cercam para a realização de seus desejos. Nesse sentido, Angela é uma protagonista dramática relativamente padrão, destacando-se pelo fato de ser uma mulher.

Por tudo isso, a relação de Angela com os espectadores e os homens da trama (seja Émile, Alfred ou os desconhecidos que a assistem na cena de strip) tem o aspecto conflitivo que envolve o protagonismo no design narrativo clássico, sem, no entanto, pender para soluções compensatórias da virtude. Angela não é uma mulher virtuosa, no sentido moral clássico, mas sim uma mulher pragmática e cheia de artifícios. Se no desenvolvimento da trama as 
atitudes mais simpáticas que ela recebeu de Émile foram ironias e deboches (uma feminista poderia descrever esta representação como a de um típico personagem machista), as respostas de Angela ao companheiro são sempre engenhosas e bem orquestradas. Essa substituição do sistema hollywoodiano de moralidade (vilania x virtude) pelo embate lúdico e cômico de Angela e Émile faz com que o filme de Godard incorpore a sedução, um dos maiores artifícios de Angela, como um conceito norteador da sua miseenscène - a cena em que Alfred corteja Angela em um café é emblemática, confirmando o poder esquivo e eficiente da personagem sobre as intenções do amigo. De certo modo, não seria um erro dizer que Une Femme est une Femme é um filme sobre o lado belicoso da sedução, ou um elogio da sabedoria envolvida no ato de sedução. Nesses dois sentidos, acreditamos que a autoconsciência da narrativa faz de Angela uma personagem complexa e irredutível à condição de objeto.

\section{Conclusão}

Ao desenvolver o projeto teórico de Laura Mulvey, Ann Kaplan esteve atenta às atualizações da linguagem do cinema de massas nas décadas que seguiram à publicação de Prazer visual e cinema narrativo. Para a autora, os anos 1980 teriam dado mostras de que a persistência da posição masculina é articulada em combinação com uma operacionalidade clássica cada vez mais refinada no plano da narrativa. As alterações de estrutura seriam bastante sutis, dialogando com as expectativas de um público que se via impactado pelas transformações dos costumes, favoráveis a muitas das causas feministas, que reposicionaram a mulher socialmente no mundo ocidental (ou no mundo influenciado pelo Ocidente).

Kaplan é especialmente sensível ao processo pelo qual, no cinema industrial, as personagens femininas passaram a controlar a ação, destinando aos personagens masculinos uma função diversa daquela que lhes era atribuída no auge do cinema hollywoodiano de estúdios (anos 1930 aos anos 1960). Em um sentido bem particular, os personagens homens também passaram a existir na condição de objetos sexuais, semelhantes às estrelas fetichizadas do star system. "Quando o homem deixa seu papel tradicional, em que controla a ação, e assume o de objeto sexual, a mulher adota o papel masculino de dono do olhar e iniciador da ação" (Kaplan, 1995, p. 51).

Essa inversão de papéis garantiria que a ideia de um olhar masculino fosse mantida e chancelada como uma posição formal e abstrata que qualquer indivíduo poderia ocupar. Nesta troca de papéis do cinema desde os anos 1980, as personagens mulheres perderam características como a bondade, a 
humanidade e a maternidade, revestindo-a da frieza e da ambição típicas do homem.

Trocando em miúdos, Kaplan sustenta que a mulher foi masculinizada para ter uma função ativa nos enredos do cinema narrativo de ampla veiculação. Mais recentemente, a atriz norte-americana Angelia Jolie pode ser vista como um dos exemplos mais explícitos deste processo observado por Kaplan, uma vez que a sua consagração como uma estrela de cinema está ligada aos vários papéis com características masculinas que ela interpretou em Hollywood (personagens violentas que dominam a ação e se impõem usando de força física, assim como ídolos masculinos de um passado recente, como Van Damme ou Schwarzenegger). Como atestam exemplos assim, o masculino e o feminino seriam dois modelos que os filmes realizam formalmente, sem que o gênero do ator ou da atriz precisem ser coerentes com os conceitos tradicionais de masculino e feminino. Para Kaplan (1995, p. 53), "as narrativas dos filmes são organizadas por meio de linguagem e discurso masculinos que paralelizam-se ao discurso inconsciente", acarretando uma reposição da mulher como homem.

O que Une Femme est une Femme pode significar em relação a estas tendências que as autoras feministas apontaram? Embora a chamada posição masculina não seja construída apenas pelo efeito de ilusão do cinema clássico, é preciso admitir que, mesmo no cinema antiilusionista de Godard, a experiência cinematográfica não sofre algum tipo de abalo capaz de revogar as condições voyeuristas da espectatorialidade. Os filmes continuam a ser exibidos em telas grandes (e cada vez mais ilusionistas) que possuem um destaque formidável no ambiente escuro e emudecido. O espectador continua, assim, a imergir em um espaço físico propício para a modalidade de prazer visual que Mulvey descreveu em 1975.

No entanto, o antiilusionismo e o elevado grau de autoconsciência da narrativa de Une Femme est une Femme conseguem reduzir a potência de ilusão da experiência, ou pelo menos transformar essa ilusão em uma autorreflexão sobre como o filme é narrado e como os personagens são representados. Godard contraria a separação entre o espectador e a diegese, integrando os olhares da câmera, dos personagens e dos espectadores ao conteúdo que deve ser apreciado de maneira distanciada e analítica. Em um filme no qual a sexualidade e as relações entre homens e mulheres são tão salientes, a linguagem moderna de Godard acaba desviando de uma crítica feminista. O tipo de protagonismo que Angela possui em Une Femme est une Femme não poderia ser explicado simplesmente pela tese kaplaniana de que as mulheres foram repostas como homens nas tramas que os anos 1980 começaram a atualizar. O filme de Godard não teria antecipado esta tendência, mas sim criado uma alternativa a ela, antes 
mesmo de o modelo clássico passar pelas revisões que Kaplan estudou em sua pesquisa.

Em Une Fermme Mariée (1964), filme posterior de Godard, o movimento feminista é referido diretamente em algumas cenas em que a protagonista, Charlotte (Macha Meríl), precisa lidar com os dilemas de ser casada e possuir um amante. Este filme propõe uma alegoria do prazer sexual feminino que mereceria análise à parte. Caminhando na rua após um encontro sexual, por exemplo, Charlotte ignora o cartaz feminista que mostra uma mulher tirando o sutiã como um gesto de libertação. A sua indiferença em relação ao feminismo não impede, contudo, que ela tenha papel ativo na ação de Une FemmeMariée, assim como Angela em Une Femme est une Fermme.

O estilo godardiano na construção destas personagem prima por uma espécie de psicologização interrogante. Elas são mulheres que possuem muitas perguntas sobre si mesmas e sobre suas relações com os homens. Charlotte ou Angela estão longe de serem militantes do feminismo, mas tampouco são acríticas quanto ao lugar que lhes cabe no mundo. Charlotte é uma personagem capaz de se preocupar se os seus seios são belos como os de uma mulher ideal, e ao mesmo tempo guardar distância das revistas femininas, como se não precisasse do que elas têm a dizer. Angela também esnoba uma edição de Marie Claire que Émile Ihe dá de presente em Une Femme est une Femme. As duas personagens se assemelham, também, por não endossarem a separação entre maternidade e sensualidade que Kaplan aponta em filmes como BlondeVenus. Michel Delahaye (1968, p. 79) parece ter bastante razão quando comenta as ambiguidades destas personagens godardianas: "no domínio da sexualidade, Godard nos provoca duplamente: face anossas obsessões, por seu puritanismo (sua pintura feroz da chama civilisation d'cul), face a nossas inibições, ao exprimir livremente o amor sexual e a necessidade desta expressão".

Tomemos a cena em que Angela está preparando os ovos para o jantar de Émile a fim de concluir nossa análise. Émile que ler o jornal. Angela pega o L'Humanité sobre a mesa e o joga sobre o companheiro, que está fora de quadro. Toma, comunista! - ela diz. Enquanto Émile protesta pelo jornal despedaçado no arremesso, Angela deixa que os ovos caiam no chão. A interpretação de Anna Karina é vacilante, fiel ao tom farsesco do filme, e nos leva a crer que a atitude da personagem foi voluntária. A câmera mergulha em busca do melhor enquadramento para mostrar Angela em uma oscilação de sentimentos. Não sei se devo rir ou chorar, ela diz a Émile, que acende um cigarro recostando-se na porta da cozinha. Ele responde: As mulheres ficam mais feias quando choram.

A frase é uma deixa para que Angela domine a cena e se expresse sobre $o$ que é ser uma mulher. $\mathrm{O}$ som de um apito é ouvido, como se a partida de futebol 
que Émile quer acompanhar estivesse se iniciando no interior da sua casa. Angela se levanta e atravessa o espaço da cena, da esquerda para a direita, até se revelar em primeiro plano para Émile. O movimento da personagem termina quando as suas costas encontram a parede da cozinha, e ela finalmente abandona o quadro, deixando o olhar judicioso de Émile em seu lugar. Não acho, diz Angela, discordando que as mulheres ficam mais feias quando choram. Em um campocontracampo durante o qual é observada pelo companheiro, ela finaliza o seu discurso:

Não há nada mais belo que uma mulher chorando.

Tem que boicotar as mulheres que não choram.

As mulheres modernas são idiotas quando pretendem elimin...

Não, não é assim. Uma mulher que não pode chorar é uma idiota.

Falo dessas mulheres modernas que tentam imitar os homens.

Estou farta de vocês. Virem-se sozinhos.

Godard não subtrai de Angela as características que, segundo a teoria feminista, tenderiam a desaparecer nas personagens mulheres dos filmes narrativos a partir dos anos 1980. Apesar de fetichizada, Angela não se masculiniza como elas. O seu discurso contra as mulheres modernas, sendo ela própria uma mulher tão moderna, é uma contradição que só se pode assimilar como a reivindicação de umahabilidosa delicadeza, utilizada pela personagem para vencer a disputa com Émile. Imitar os homens não seria uma alternativa. Os traços femininos clássicos de Angela permanecem, e a personagemnão adquire a frieza e a ambição masculinas para se colocar no controlar a ação. Até certo ponto, Angela possui uma rigidez psicológica que lhe imprime grande clareza de objetivos e de personalidade. Todavia, ela também preserva uma profundidade que mesmo a narrativa autoconsciente de Une Femme est une Femme é incapaz de desvendar por completo, confirmando-a como uma personagem moderna4.

O último diálogo do filme propõe que as características de Angela têm algo a ver com a essência do feminino. A ideia de que uma mulher é uma mulher, presente no título da obra, reproduz a resposta que a personagem dá a Émile quando é acusada de ser infame. Servindo-se de um trocadilho da língua francesa, ela responde: Jene suis pasinfâme, je sui une femme $\mathbf{f}^{5}$. Naturalmente, a

4 Pensamos aqui nos ensaios sobre o cinema moderno de Rogério Sganzerla (2001, p. 60): "O filme moderno não tenta explicar e definir o interior do personagem [...] Não é possível conhecer todo o interior de um personagem. O que acontece são ligeiras erupções e facetas que o autor não impõe, não diz nada, insinua".

5 Eu não sou infame, sou uma mulher. 
provocação sobre a essência da mulher é pura retórica, e a resposta de Angela é predestinada a ser evasiva, deixando no ar um enigma. Não por acaso, o título do filme é uma tautologia. Que uma mulher seja uma mulher só pode explicar a dificuldade de definir o feminino. Mas se o cinema já foi capaz de produzir personagens que se aproximam desta resposta, Angela deve ser uma delas.

\section{REFERÊNCIAS}

BORDWELL, David. Classical Hollywood Cinema: Narrational Principles and Procedures. In: ROSEN, Philip. A Film Theory Reader: Narrative, Apparatus, Ideology. New York: Columbia University Press, 1986.

Narration in the Fiction Film. Wisconsin: The University of Wisconsin Press, 1985.

DELAHAYE, Michel. Jean-Luc Godard ou a infância da arte. In: BARBOSA, H. Jean-Luc Godard. Rio de Janeiro: Record, 1968.

KAPLAN, E. Ann. A mulher e o cinema: os dois lados da câmera. Rio de Janeiro: Rocco, 1995.

MALUF, S.W.; MELLO, C.A.; PEDRO, V. Políticas do olhar: feminismo e cinema em Laura Mulvey. Revista Estudos Feministas, Florianópolis, v. 13, n. 2, p. 343-50, ago. 2005.

MULVEY, Laura. Reflexões sobre'Prazer Visual e Cinema Narrativo' inspiradas por Duelo ao Sol, de King Vidor (1946). RAMOS, Fernão (Org.). Teoria Contemporânea do Cinema. São Paulo: Senac, v.1, p. 381-392, 2005.

Prazer Visual e Cinema Narrativo. In: XAVIER, Ismail. A Experiência do Cinema. Rio de Janeiro: Edições Graal, 2003, p. 437-53.

SGANZERLA, Rogério. Por um Cinema sem Limite. Rio de Janeiro: Azougue Editorial, 2001.

STAM, Robert. O Espetáculo Interrompido: literatura e cinema de desmistificação. Rio de Janeiro: Paz e Terra, 1981.

XAVIER, Ismail. O Olhar e a Cena: melodrama, Hollywood, Cinema Novo, Nelson Rodrigues. São Paulo: Cosac Naify, 2003.

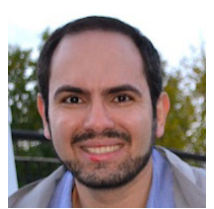

Endereço do autor:

Rodrigo Cássio Oliveira <rodcassio@hotmail.com>

http://lattes.cnpq.br/0545897116631093

Universidade Estadual de Goiás (UEG).

Avenida Professor Alfredo de Castro s/nº - Bairro Chácara do Governador

74870-038 - Goiânia - GO - Brasil 